\title{
A MELHORIA DO PROCESSO ENSINO - APRENDIZAGEM DAS CIÊNCIAS PARTINDO DA REFLEXÃO DIALÓGICA DAS CONCEPÇÕES E DAS PRÁTICAS ENTRE PROFESSOR E ORIENTADOR
}

Leonel Jorge Ribeiro Nunes

Professor do ISEIT-Mirandela, Portugal

\section{A DIDÁCTICA DAS CIÊNCIAS CENTRADA NO PROCESSO DE ENSINO}

Presentemente assiste-se à consolidação da Didáctica das Ciências como uma área específica do saber que estrutura as contribuições da Psicologia, da Sociologia, da Filosofia, da Historia, da Linguística e de outras Ciências em relação ao processo de Ensino-Aprendizagem das Ciências (Furió, 1994; Gil, 1994; Martinand, 1994; Porlán, 1993, Joshua \& Dupin, 1993; Hodson, 1992; Porlán, 1992; Sanmartí, 1992).

A Didáctica das Ciências tem como objectivo central a explicação de problemas relacionados com o Ensino-Aprendizagem científico e a procura de caminhos para os superar. Esta disciplina tem-se centrado no estudo dos processos que levam o estudante a aprender numa perspectiva construtivista. Porém, surge uma nova mudança de perspectiva: muitos autores passam a ter no plano central das suas indagações o processo de ensino e, vinculado a isto, a preocupação com a formação dos professores (Briscoe \& Peters, 1997; Appleton \& Asoko, 1996; Bol \& Strage, 1996; Coble \& Koballa, 1996; Fedock et al., 1996; Strage \& Bol, 1996; Tobin \& Tippins, 1996; Anderson \& Mitchener, 1994): “...se se pesquisa o que pensa e faz 0 aluno na aula para o que pensa e faz o professor, procurando analisar a sua actividade e assim poder decifrar o seu desenvolvimento profissional, em particular, haverá que determinar quais são as suas necessidades formativas e que factores podem influenciar uma contínua preparação para a mudança didáctica" (Furió, 1994).

Enquanto a aprendizagem constitui o privilégio de uma classe social privilegiada económica, social e culturalmente, o ensino dirige-se àqueles alunos que aprendem de qualquer maneira, aqueles "imunes ao tipo de professor", o meio socio-cultural de que procedem faz com que os problemas do processo EnsinoAprendizagem sejam disfarçados. Haveria que matizar sobre o que se compreende por "aprender", pois é bastante comum que uma aprendizagem com sucesso signifique retenção da informação transmitida para ser repetida sem que isso implique compreensão significativa do conhecimento. A visão do processo Ensino-Aprendizagem que se adoptou neste trabalho afasta-se dessa concepção e entende a aprendizagem como um processo de construção de um conhecimento significativo e relevante para a vida dos alunos. Este processo, que vincula as novas concepções a serem trabalhadas com as já elaboradas pelos alunos, começa na acção social "com os outros" e deve avançar até a incorporação pessoal do mesmo. A actual conjuntura político-económica-social está a exigir um novo paradigma de escola e de educação que contemple uma nova relação entre desenvolvimento e democracia, cujo eixo norteador seja uma nova concepção de sujeito.

Outro aspecto a destacar é que a própria evolução exponencial da Ciência e da Tecnologia que se produziu nas últimas décadas, influencia, necessariamente, a educação científica. O movimento educativo CTS - Ciência, Tecnologia e Sociedade (Solbes \& Vilches, 1995; Stiefel, 1995) pretende promover a alfabetização em Ciência e Tecnologia de todos os cidadãos, para que estes possam participar no processo 
democrático da tomada de decisões e na resolução de problemas relacionados com a Ciência e a Tecnologia na nossa sociedade. Assim, propõe-se atingir a formação de cidadãos científica e tecnologicamente alfabetizados, capazes de tomar decisões fundamentadas e acções responsáveis, atingir pensamento crítico e independência intelectual. Hoje não se justifica uma educação como "simples transmissão de informações" que podem ser procuradas no computador e que variam em poucos anos. Hoje atinge importância o aprender a pensar, a reflectir, a ser criativo, "aprender a aprender". E tudo isto, no marco amplo de uma educação democrática.

É com base nas idéias expostas que se orienta esta pesquisa em que se tenta colaborar na abertura de um caminho que se centre na formação continua dos professores de Ciências e que incida na melhoria educativa no âmbito da Didáctica das Ciências. O objectivo desta pesquisa foi "desenvolver um método de formação didáctica do professor de Ciências que, partindo das suas concepções e práticas, favoreça uma tomada de consciência e de decisões que por sua vez gerem melhorias no processo de Ensino-Aprendizagem na aula".

\section{BASES TEÓRICAS DA FORMAÇÃO DIDÁCTICA DO PROFESSOR DE CIÊNCIAS}

"Formação Didáctica do professor de Ciências", é uma expressão genérica que alberga, concepções variadas que respondem a um conjunto de argumentos opináveis, alguns complementares, outros contraditórios. Como diz Shulman (1989), a existência na área educativa de diferentes modelos e programas de investigação que se sucedem e coexistem, não é uma debilidade da área senão uma interessante tendência que permite ter em conta uma ampla gama de determinantes que influenciam a prática do ensino e as suas consequências. Para este autor "para as ciências sociais, a coexistência de escolas divergentes de pensamento é um estado natural e bastante maduro" (Shulman, 1989). Da mesma maneira Merton (1975) advoga pela superioridade de uma pluralidade de paradigmas em discussão à hegemonia de uma única escola de pensamento. Defende as vantagens de uma pluralidade de orientações teóricas que denomina de "ecleticismo disciplinado" (Merton, 1975).

Como aspecto inicial aponta-se a preocupação de encontrar um caminho para que a investigação didáctica se pudesse ligar directamente à Formação dos professores. Pretendia-se realizar uma pesquisa que tivesse a sua fundamentação teórica estreitamente vinculada ao campo específico de actuação dos professores.

Deste modo faz-se uma proposta que se afasta da solução da Formação dos professores através de cursos ou seminários. Ainda que os assuntos tratados fossem de grande importância e relevantes para a sua formação, nessa solução, a formação corre o risco de ser algo externo, algo que o professor terá que integrar, por sua conta, no seu espaço de actuação. Quer dizer que, deste modo, ainda que o professor se fundamente teoricamente, muito provavelmente isto ficará como um simples discurso, não será incorporado na prática quotidiana das suas aulas.

\section{O PROFESSOR COMO SUJEITO CRÍTICO REFLEXIVO. PERSPECTIVA DE RECONSTRUÇÃO SOCIAL}

$\mathrm{Na}$ concepção reconstrucionista social reflexiva a atenção do professor está centrada tanto na sua própria prática, quanto nas condições sociais em que essa prática se concretiza. A prática reflexiva nesta 
perspectiva tem em conta questões relativas 市 dimensões sociais e políticas do seu exercício docente. Uma outra caraterística desta concepção, (Zeichner, 1995) é o compromisso com a idéia da reflexão enquanto prática social. Trata-se de criar comunidades de aprendizagem nas quais os professores, como grupo, apoiem o progresso de cada um.

Vinculado a esta perspectiva deve-se propor como objectivo prioritário, tanto para os docentes como para os alunos promover a capacidade de pensar criticamente. Zeichner (1987), Kemmis (1993), Carr (1996), Carr \& Kemmis (1988) são expoentes do desenvolvimento desta perspectiva. Estabelece-se como objectivo final deste trabalho a criação de uma comunidade crítica de professores de Ciências que se apoiem na tomada de consciência e de decisões com o objectivo de atingir um processo de EnsinoAprendizagem da Ciência significativo e relevante para a vida dos estudante enquanto sujeitos críticos. TAILOR (1982) expõe três condições para a existência de uma comunidade:

- compartilhar valores e crenças;

- que se estabeleçam relações directas e múltiplas entre as pessoas;

- que essas relações se caracterizem por uma reciprocidade equilibrada em que os actos individuais beneficiem todos, existindo um sentimento de solidariedade, fraternidade e consideração mútua.

Kemmis (1993) diz que para que um grupo de pessoas chegue a ser uma comunidade "crítica", deve, em primeiro lugar, cumprir os pré-requisitos de ser uma comunidade. Porém, além disso, deve dar-se uma reflexão deliberadora que problematize questionando o contexto.

Nesta proposta de Formação dos professores, a partir de um marco referencial a respeito do processo de Ensino-Aprendizagem das Ciências realiza-se uma reflexão deliberadora confrontando as concepções e práticas do professor com esse marco de referência. $O$ processo central, no inicio do projecto, é a reflexão dialógica co-regulada entre o orientador e cada professor. Porém também desde o inicio se vão evidenciando acções que promovam que o conjunto de professores que participa no projecto formem uma comunidade onde, em forma mútua, estabelecem uma verdadeira comunidade auto-regulada que realiza um processo metacognitivo de tomada de consciência e, a partir do mesmo, tomada de decisões dentro do campo da Didáctica das Ciências.

Nesta visão, a pesquisa não se relaciona com um produto recebido já elaborado para ser implantado "no escuro" e exige-se que o pesquisador procure auxiliar para que os professores organizem as suas concepções e as suas práticas, orientando a formação de juízos fundamentados a respeito da actividade profissional e consequentemente a tomada de decisões reflexivas.

\section{METACOGNIÇÃO, E MUDANÇA CONCEPTUAL NA FORMAÇÃO DOS PROFESSORES}

Metacognição e mudança conceptual são conceptualizações a partir das quais surgem interessantes propostas que pensam a Formação dos professores como um processo de mudanças a respeito dos significados do seu ensino. Este modelo, por sua vez, é coerente com as actuais propostas a respeito do processo de Ensino-Aprendizagem da Ciência. 
Nesta pesquisa, o assunto central da construção da mudança conceptual é reconhecer que qualquer mudança está nas mãos do próprio professor. Ele tem que reconhecer as idéias relevantes, após avaliar essas idéias (concepções, percepções, crenças e habilidades), em termos do que está a ser refletido, entender quais são as decisões alternativas possíveis e, a partir disso, decidir se reconstroi as suas idéias. Aprender requer a disposição (consentimento e disponibilidade) e a actividade de quem aprende.

Afirmar que o professor, por si mesmo, deve reconhecer, avaliar e decidir se faz ou não a reconstrução, não implica que está a diminuir o papel do orientador. Pelo contrário, dá-lhe o papel de promover as actividades capazes de conseguir o reconhecimento, avaliação e decisões por parte do professor.

Outro aspecto a destacar é que as mudanças conceptuais raramente significam o completo abandono de uma noção em favor de outra, geralmente significam a adição de novas noções, a retenção de noções já existentes e a aquisição da noção do contexto no qual a nova noção é mais apropriada. Portanto, este trabalho concretiza-se como um processo lento, a longo prazo e contextualizado.

O conceito de metacognição refere o facto de os professores terem a informação e a autodirecção para se aproximar do reconhecimento, avaliação e decisão de se irão, ou não, reconstruir as suas idéias. Isto implica que para tomar as decisões é necessário levar a cabo uma reflexão do tipo metacognitiva. Por isso, os conceitos de mudança conceptual e metacognição são totalmente interdependentes (Gunstone \& Northfield, 1994).

O aspecto crucial de como é entendida a mudança conceptual baseia-se no facto de os professores elaborarem decisões fundamentadas teoricamente baseadas na reconstrução das suas concepções pessoais, percepções, crenças e práticas.

Nesta posição, as idéias fundamentadas implicam possuir os conhecimentos e as habilidades necessárias para que a mudança seja metacognitiva. Como consequência a aprendizagem de conhecimentos didácticos e a aprendizagem de estratégias metacognitivas são tarefas inseparáveis e interdependentes.

Por outro lado, devem-se facilitar as condições que "estimulem" os professores a assumir o risco intelectual que pressupõe esta abordagem, e que se pode relacionar com outra linha de trabalho fundamental: 0 apoio aos professores para que assumam as decisões. No decurso deste trabalho fala-se em assumir decisões e não inovações. Esta terminologia tem a sua justificativa no principio de que todo o processo metacognitivo deve ir acompanhado do fortalecimento da autoestima do professor. Consequentemente, o processo de reconhecimento não se deve apoiar apenas naquilo que se pretende inovar, mas também naqueles aspectos que se considerem positivos e portanto se queiram preservar. Ao centrar a acção tanto no inovar como no preservar, esta dupla perspectiva, é coerente com que o processo fortaleça a autoestima do professor.

\section{A MEDIAÇÃO DA REFLEXÃO DIALÓGICA CENTRADA NUM CONTEXTO SOCIO-CULTTURAL ESPECÍFICO NA FORMAÇÃO DOS PROFESSORES}

A concepção deste trabalho não se centra em processos individuais de autoreflexão mas sim na reflexão dialógica produto de um processo co-regulado, em primeiro lugar entre cada professor e o 
orientador e que tem como intenção última, a criação de uma comunidade crítica de reflexão e acção a respeito do processo de Ensino-Aprendizagem da Ciência, situando-se no contexto sociocultural de trabalho na comunidade.

Para um adequado desenvolvimento profissional centrado na mudança das concepções e das práticas dos professores, precisa-se da colaboração de colegas que auxiliem a ter evidências das próprias construções (Villar, 1988). Essa colaboração num primeiro momento, dá-se entre cada professor e o orientador, pois os modelos didácticos dos professores são muito díspares e crê-se necessário estabelecer um apoio do colega (orientador) que já tenha refletido a respeito dos actuais modelos do processo de Ensino-Aprendizagem da Ciência. As sucessivas fases do trabalho vão orientando o processo cada vez mais rumo a uma regulação mútua entre professores autónomos que se apoiam até à própria auto regulação do processo.

Angulo (1990) também fala neste sentido destacando o "coleguismo" como premissa da colaboração docente, expressando que o processo de formação melhora quando se participa em actividades que impliquem relações e apoios mútuos e diálogos interpessoais. O interesse, a motivação e a capacidade cresce quando existe comunicação para descrever as experiências de classe, compartilhar o conhecimento pessoal das situações educativas, planear tarefas e trocar os êxitos atingidos.

A interacção social na aula é um dos tema de interesse actual (Candela, 1996; Cazden, 1991; Edward \& Mercer, 1988). A respeito deste assunto realça-se a necessidade de estudar o papel da linguagem e da acção social na elaboração do pensamento. Estas idéias são apresentadas nos trabalhos de Vygotsky e seus discípulos, (Vygotsgy, 1989; Wertsch, 1988, 1993), que falam das origens socioculturais e linguísticas do pensamento conceptual, da importância da acção social comunicativa na aprendizagem. Através da linguagem desenvolvem-se os conceitos como membros dos diversos mundos "sociais" em que se podem encontrar. Ao falar e ao escutar percebe-se o que é necessário conhecer, fazer e dizer nesse âmbito da vida social e pode-se manifestar a competência necessária para se ser aceite como membros (Edwards \& Westgate, 1987).

A busca de novos modelos que, sem deixar de lado outros aspectos, analisem aspectos da acção social e da comunicação, sobretudo verbal, oferece um valioso marco de referência para trabalhar no processo de formação dos professores.

\section{A CONSTRUÇÃO DO CONHECIMENTO NA ZDP DE CADA PROFESSOR}

A conceptualização de ZDP - Zona de Desenvolvimento Proximal - está na moda nos actuais estudos educativos, pelo menos nos que se orientam pela teoria sociocultural. Isto, por um lado, faz com que o conceito seja conhecido, porém, por outro lado corre o risco de que "o modismo" o deforme e até se transforme em algo usado com pouco rigor. Por isso inicia-se esta secção definindo ZDP para que se compreenda em que sentido se utiliza neste trabalho.

O conceito de ZDP é elaborado por Vygotsky (1989a) em relação aos seus estudos com crianças, porém, o seu potencial é genérico e, neste caso, aplica-se àrelação que se estabelece entre o orientador e cada professor. Vygotsky estabelece uma diferenciação entre o desenvolvimento que se produz em situações de aprendizagem não sistematizada e a aprendizagem escolar sistemática. Afirma que a diferença não resulta exclusivamente da sistematização e para a caracterizar introduz o conceito de ZDP. " $A$ 
zona de desenvolvimento proximal é a distância entre o nível de desenvolvimento real, que se costuma determinar através da solução independente de problemas e o nível de desenvolvimento potencial, determinado através da solução de problemas sob a orientação de um adulto ou em colaboração com colegas mais capacitados". Como diz Cazden (1981), a zona possibilita a actuação antes da competência. Moll (1993) considera que a zona não é apenas uma heurística instrutiva inteligente, senão uma construção teórica chave que coloca o indivíduo dentro de uma situação concreta de aprendizagem e desenvolvimento. Os estudos relacionados com a ZDP permitem estudar, ao contrário de processos já fossilizados, a formação dos processos analisando os sujeitos em actividade. Vygotsky (1989a) afirmava que este método permitia aceder aos processos ocultos que apenas se manifestam nas acções de um sujeito com o meio, a dinâmica social da mudança. Minick (1987) fala da transição da consideração do indivíduo enquanto indivíduo àconsideração do indivíduo enquanto em actividade social.

Este conceito de ZDP tem orientado tanto a forma de entender a relação inicial entre professor e orientador, como a relação em grupo entre os professores, onde uns se destacam como colegas que têm avançado mais na consideração das modernas concepções do processo Ensino-Aprendizagem da Ciência que outros. No caso deste trabalho, no momento inicial, tem-se procurado uma interdependência entre o trabalho do orientador e de cada professor, de maneira que a reflexão dialógica, elemento mediador, transcorra levando cada um a actuar dentro da sua ZDP.

A tónica é analisar a existência de decisões inovadoras ou a tomada de consciência daquelas que se quer preservar, "actividades qualitativamente novas", ainda que no momento inicial todavia possam permanecer co-reguladas entre professor e orientador em lugar de ser auto-reguladas pelo professor. " $A$ atenção não está na transferência de habilidades dos que sabem mais aos que sabem menos, mas sim no uso colaborativo das formas de mediação para criar, obter e comunicar o sentido" (Moll, 1993).

Finalmente ressalta-se que é este trabalho na ZDP o que dá sentido à necessidade de dar prioridade, neste modelo de formação dos professores, a um momento inicial de reflexão individualizada orientador-professor. Parte-se da hipótese de que os modelos habituais que se iniciam por "orientadorGrupo de professores" dificultam o trabalho em profundidade na ZDP e por isso, habitualmente, se produzem poucas mudanças.

\section{RESULTADOS OBTIDOS}

Neste trabalho tem-se chegado a resultados sobre um método de formação continua de professores de Ciências, através da primeira fase de uma pesquisa com professores de Geologia e Biologia do Ensino Básico e Secundário da cidade de Coimbra. Ainda que se pense na Formação Inicial e Continua dos professores como processos inseparáveis, existem também características que os especificam, e este trabalho centra-se na Formação Continua dos professores.

O objectivo proposto foi, orientados por um marco teórico referencial, levar àtomada de consciência e de decisões que por sua vez gerassem melhorias no processo de Ensino-Aprendizagem das Ciências na aula. Esse processo significa mudanças nas concepções e nas práticas dos professores que esteve unido a processos metacognitivos de tomada de consciência.

O modelo de Formação Didáctica dos professores que se adoptou foi trabalhar com o professor como um sujeito reflexivo e crítico. Neste trabalho existiu um marco teórico, estruturado a partir de uma 
tomada de posições fundamentadas em concepções que incluem uma visão do Homem, da Sociedade, da Ciência e do processo Ensino-Aprendizagem, dentro dos limites em que se orientou a acção e no momento final dessa primeira etapa verificou-se que já era compartilhado pelos professores.

O método foi delineado para a formação de professores de Ciências Naturais em comunidades de tamanho médio, como é o caso da cidade de Coimbra.

No projecto não se fala de "facilitador", mas sim de orientador. Isto significou uma matiz de acção mais directiva. Parte-se da idéia de um encontro no espaço do qual se estabeleceu uma negociação. Porém nessa negociação, o orientador era portador de idéias explícitas relacionadas com um marco teórico no espaço a partir do qual actuar e, geralmente, o professor era portador de idéias implícitas. Por isso se defendeu a postura de que existe uma posição de orientação e não somente de facilitação do processo, ainda que esta não seja imposta e sim negociada.

Procurou-se que cada professor, dentro de sua ZDP, evoluisse nas suas representações e na sua prática a respeito do processo de Ensino-Aprendizagem da Ciência. Para promover esta autorregulação partiu-se de actividades pensadas de forma co-regulada. Um processo desta natureza significou gerar habilidades metacognitivas que permitissem a auto-regulação e implicou que o objectivo fosse conseguir que os professores chegassem a ser autónomos, ou seja, que não necessitassem da "facilitação" por parte do orientador (Bruner, 1988 ).

O processo de trabalho teve em conta o fortalecimento da autoestima de cada professor, unido ao apoio mútuo entre os integrantes do grupo. A finalidade última do processo era, e é, a criação de uma comunidade crítica, de professores de Biologia e Geologia do Ensino Básico e Secundário da cidade de Coimbra, neste caso experimentado.

Ao mesmo tempo, em relação a este aspecto, toda a acção procurou não destacar apenas aqueles aspectos do trabalho a respeito dos quais inovar, senão também a continuidade consciente de concepções e práticas coerentes com o marco de referência. Ou seja, que através de um intercâmbio reflexivo entre cada professor e o orientador, se chegasse a um reconhecimento, avaliação e tomada de decisões, realizadas conjuntamente, de "o que se considerou válido" e o que foi necessário inovar nas práticas e concepções de cada professor. Pensa-se que se o trabalho apenas se centrasse nas inovações poder-se-ía chegar a destruir a autoestima do professor já que este poderia chegar a ser tão crítico com seu trabalho que ao contrário de avançar ficaria bloqueado.

Considera-se que o processo metodológico que orientou o trabalho resultou efectivamente. Especialmente a utilização de encontros dialógicos, entendidos como os espaços propícios para orientar a negociação entre o orientador e o professor, de maneira que se efectuasse uma reflexão crítica das concepções e prática (pensamento e acção), do professor, vinculado ao contexto real que o condiciona.

Acredita-se que o processo de Formação Continua estruturado é lento e os seus resultados podem demorar anos a concretizar. É por isso que se inclui a conotação de processo inacabado, é a primeira fase de um processo que terá continuidade por um tempo prolongado. Talvez o principal argumento negativo que se poderia esgrimir a respeito de um método de Formação de professores com estas características é a lentidão com a qual se vão evidenciando as mudanças. 
De acordo com a experiência actual, entende-se que este método é válido. A intenção de legislar novas directrizes para a educação, se não são acompanhadas de um trabalho directo com os professores, podem ficar como boas propostas no papel, porém não se conseguem concretizar efectivamente ao chegar à prática. Também os cursos de reciclagem podem levar a atitudes de entusiasmo durante o curso, contudo, ao regressar àsituação de aula, a prática seguidamente torna a cair nas velhas rotinas que se procuraram superar.

Os resultados deste trabalho levam a afirmar-se que a estratégia de um encontro dialógico com os professores resulta eficaz. Esta estratégia forma parte de um processo de mudanças lentas. Porém permite adequar-se à individualidade de cada professor, levando -os a um processo crítico com implicações consciencialização e na participação da tomada de decisões. Como resultado dessas características vão-se produzindo mudanças lentas, mas persistentes.

\section{BIBLIOGRAFÍA}

Anderson, R. D. \& MitcheneR, C. P. (1994), "Research on science teacher education", Handbook of research on sicience teaching and learning, Nova York, E.U.A.

ANGULO, J. F. (1990), "Investigación-acción y curriculum: una nueva perspectiva en la investigación educativa", Investigación en la Escuela, n.ำ11, pp. 39-49.

Appleton, K. \& AsoKo, H. (1996), "A case study of teacher's progress toward using a constructivist view of learning to inform teaching in elementary science", Science Education, n. 80 (2), pp. 165-180.

Bol, L. \& Strage, A. (1996), "The contradiction between teachers'instructional goals and their assessment practices in high school biology courses", Science Education, n.. 80 (2), pp. 145-163.

Briscoe, C. \& Peters, J. (1997), "Teacher collaboration across and within schools: supporting individual change in elementary science teaching", Science Education, n... 81 (1), pp. $51-65$.

BRUNER, J. S. (1988), “Desarrollo Cognitivo y Educación”, Morata, Madrid.

Candela, A. (1996), "La contrucción de la ciencia en la interacción discursiva del aula", Centro de Investigación y de Estudios Avanzados del Instituto Politécnico Nacional de México, n.․ 42, pp. 34 78.

CARR, W. (1996), “Una teoría para la educación. Hacia una investigación educativa crítica.", Morata, Madrid.

CARR, W. \& KEMMIS, S. (1988), "Teoria crítica de la enseñanza. La investigación acción en la formación del profesorado", Martinez Roca, Barcelona.

Cazden, C. B. (1991), "El discurso en el aula - El lenguaje de la ensenanza y del aprendizaje", Paidós MEC, Barcelona.

CAzden, C. (1981), "Performance before competence: assistance to child discourse in the zone of proximal development", Quarterly newsletter of the laboratory of comparative human cognition, $\mathrm{n} . .03$ (1), pp. 5-8.

Coble, C. R., \& Koballa, T. R. (1996), "Science Education", in SikUla, J., Buttery,T.J. \& Guyton, E.(ed), Handbook of Research on Teacher Education, E.U.A. 
EdwARDS, D. \& Mercer, N. (1988), "El conocimiento compartido. El desarrollo de la comprensión en el aula", Paidós-MEC, Barcelona.

EdWARDS, D. \& Westgate, D. (1987), "Investigating classroom talk", Palmer, London.

Fedock, P. M., Zambo, R. \& Cobern, W.W. (1996), "The professional development of college science professors as science teacher educators", Science Education, n. 80 (1), pp. 5-19.

FuRIO, C. (1994), "Tendencias actuales en la formación del profesorado de ciencias", Enseñanza de las Ciencias, n. 12 (2), pp. 188-199.

GIL, D. (1994), "Diez años de investigación en didáctica de las ciencias: realizaciones y perspectivas", Revista de enseñanza de las ciencias, n.. 12 (2), pp. 154-164.

Gunstone, R. F. \& NoRThField, J. (1994), "Metacognition and learning to teach", International Journal of Science Education, vol. 16, ํㅜ 5, pp. 523-537.

HODSON, D. (1992), "In search of a meaningful relationship: an exploration of some issues relating to integration in science and science education", International Journal of Science Education, n.․ 14 (5), pp. 541-566.

JoshuA, S. \& DupIN, J. J. (1993), "Introduction àla Didactique des sciencies et des mathématiques", Presses Universitaires de France, Paris.

KEMMIS, S. (1993), "La formación del profesor y la creación de comunidades críticas de profesores", Investigación en la Escuela, n.․ 19, pp. 15-38.

MARTINAND, J. L. (1994), "La didáctica de las ciencias y la tecnologia y la formación de profesores"., Investigación el la Escuela, n.․․ 24, pp. 59-70.

MeRton, R. K. (1975), "Structural analysis interacciones sociology", in BLAU, P. (Ed) "Approaches to the estudy of social structure", The Free Press, Nova lorque.

MINICK, N. (1987), "Implications of Vygotsky's theories for dynamic assessment", in LIDZ, C. S., "Dynamic assessment: an interactional approach to evaluating learning potential”, Longman, Nova lorque.

MoLL, L. C. (1993), "Introducción a la didáctica”, Aique, Buenos Aires.

Porlán, R. (1992), "La identidad epistemológica de la didáctica de las ciencias experimentales", Actas del Congreso Las didácticas específicas en la formación del profesorado de Santiago de Compostela, pp. 251- 258.

PORLÁN, R. (1993), "La didáctica de las Ciencias. Una disciplina emergente”, Cuadernos de Padagogía, n.ำ 210, pp. 68-71.

SANMARTí, N. (1992), "Reflexions entorn de l'evolució de la innovació i la recerca en l'ensenyament de les ciències a Catalunya", Eumo Editorial, Barcelona.

SOLBES, J. \& VILCHES, A. (1995), “El profesorado y las actividades CTS”, Alambique, n. 3, pp. 30-38.

Stiefel, B. M. (1995), “La naturaleza de la ciencia en los enfoques CTS”, Alambique, n.․ 3, pp. 19-29. 
ShULMAN, L. S. (1989), "Paradigmas y programas de investigación en el estudio de la enseñanza: una perspectiva contemporánea", in WITTROCK, "La investigación de la enseñanza, I- Enfoques, teorías y métodos", Paidós, Barcelona.

Strage, A. A. \& BoL, L. (1996), "High school biology: what makes it a challenge for teachers?", Journal of Research ing Science Teaching, n. 33 (7), pp. 753-772.

TAILOR, M. (1982), "Community, anarchy and liberty”, Cambridge University Press, Cambridge.

TOBIN K. \& TIPPINS, D. (1996), "Metaphors as seeds for conceptual change and the improvement of science teaching", Science Education, n.ㅇ 80 (6), pp. 711-730.

VILLAR, L. M. (1988), "Conocimiento, creencias y teorías de los profesores. Implicaciones para el curriculum y la formación del profesorado", Marfil, Buenos Aires.

VYGOTSKI, L. S. (1989), "Pensamento e Linguagem”, Martins Fontes, São Paulo.

VYGOTSKI, L. S. (1989a), "A formação social da mente. O desenvolvimento dos processos psicológicos superiores", Martins Fontes, São Paulo.

WERTSCH, J. V. (1988), "Vygotski y la formación social de la mente”, Paidós, Barcelona.

WERTSCH, J. V. (1993), "Voces de la mente. Un enfoque sociocultural para el estudio de la acción mediada", Visor, Madrid.

ZEICHNER, K. M. (1995), "Los profesores como profesionales reflexivos y la democratización de la reforma escolar", in FUndAción PAIDEIA, "Volver a pensar la educación (Vol II). Prácticas y discursos educativos (Congeso Internacional de Didáctica)", Morata, Madrid.

ZEICHNER, K. M. (1987), "Enseñanza reflexiva y experiencias de aula en la formación del profesorado", Revista de Educación, n.. 282, pp. 161-189. 